\title{
Determination of Diphenylamine Antioxidants in Wastewater/Biosolids and Sediment
}

\author{
Zi-Feng Zhang ${ }^{1,2,3^{*}}$, Xue Zhang1,2, Ed Sverko ${ }^{1,2}$, Christopher H. Marvin ${ }^{3}$, Karl J. \\ Jobst $^{4}$, Shirley Anne Smyth ${ }^{3}$, Yi-Fan Li ${ }^{1,2,5}$ \\ ${ }^{1}$ International Joint Research Center for Persistent Toxic Substances (IJRC-PTS), \\ State Key Laboratory of Urban Water Resource and Environment, Harbin Institute \\ of Technology, Harbin 150090, China
}

${ }^{2}$ International Joint Research Center for Arctic Environment and Ecosystem (IJRC-AEE), Polar Academy, Harbin Institute of Technology, Harbin 150090, China

${ }^{3}$ Environment and Climate Change Canada, Science and Technology Branch, 867 Lakeshore Road Burlington, ON, L7S1A1, Canada

${ }^{4}$ Ontario Ministry of the Environment and Climate Change, 125 Resources Road, Toronto, ON M9P 3V6, Canada

${ }^{5}$ IJRC-PTS-NA, Toronto, M2N 6X9, Canada

*Corresponding authors: International Joint Research Center for Persistent Toxic Substances (IJRC-PTS), State Key Laboratory of Urban Water Resource and Environment, Harbin Institute of Technology, 73 Huanghe Road, Nangang District, Harbin 150090, Heilongjiang, China.

Tel. +86-451-8628-9130.

Email address: zifeng_zhang@aliyun.com (Z.F. Zhang) 
Fig S1. (a) 2-Propanone, reaction products with diphenylamine (PREPOD); (b)

1,4-Benzenediamine, N,N'-mixed phenyl and tolyl derivatives (BENPAT); (c)

Benzenamine, N-phenyl-, reaction products with styrene and 2,4,4-trimethylpentene (BNST)

Fig S2. Nine collection sites of sediment samples \& 8 wastewater treatment plants' locations in the south of Ontario in Canada

Fig S3. Chromatogram (GC-MS, full scan mode) of BNST

Fig S4. MS/MS chromatogram of LOD for all target compounds 
a

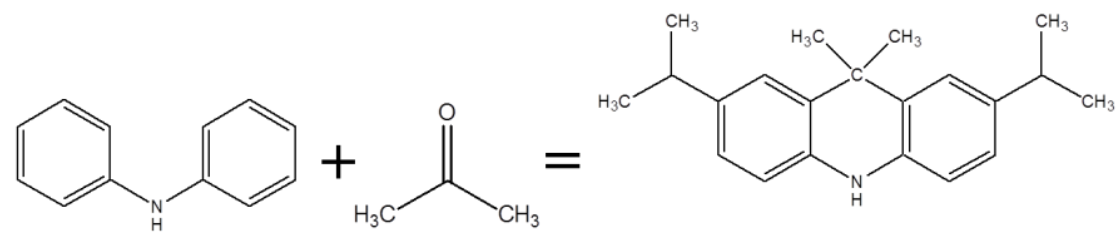

1-3 substitutions of $\mathrm{C} 3 \mathrm{H} 7$ b<smiles>Cc1ccccc1F</smiles><smiles>CCc1ccccc1C</smiles><smiles>C#CC(C)(C)CC(=C)CCC=Cc1ccc(I)cc1</smiles><smiles>CC(C)c1cccc(Nc2ccc(O)cc2Nc2cccc(C(C)c3ccccc3)c2)c1</smiles>

$0-2$ substitutions of $\mathrm{C} 8 \mathrm{H} 17$ and $\mathrm{C} 8 \mathrm{H} 9$

Fig S1. (a) 2-Propanone, reaction products with diphenylamine (PREPOD); (b)

1,4-Benzenediamine, N,N'-mixed phenyl and tolyl derivatives (BENPAT); (c) Benzenamine, N-phenyl-, reaction products with styrene and 2,4,4-trimethylpentene (BNST) 


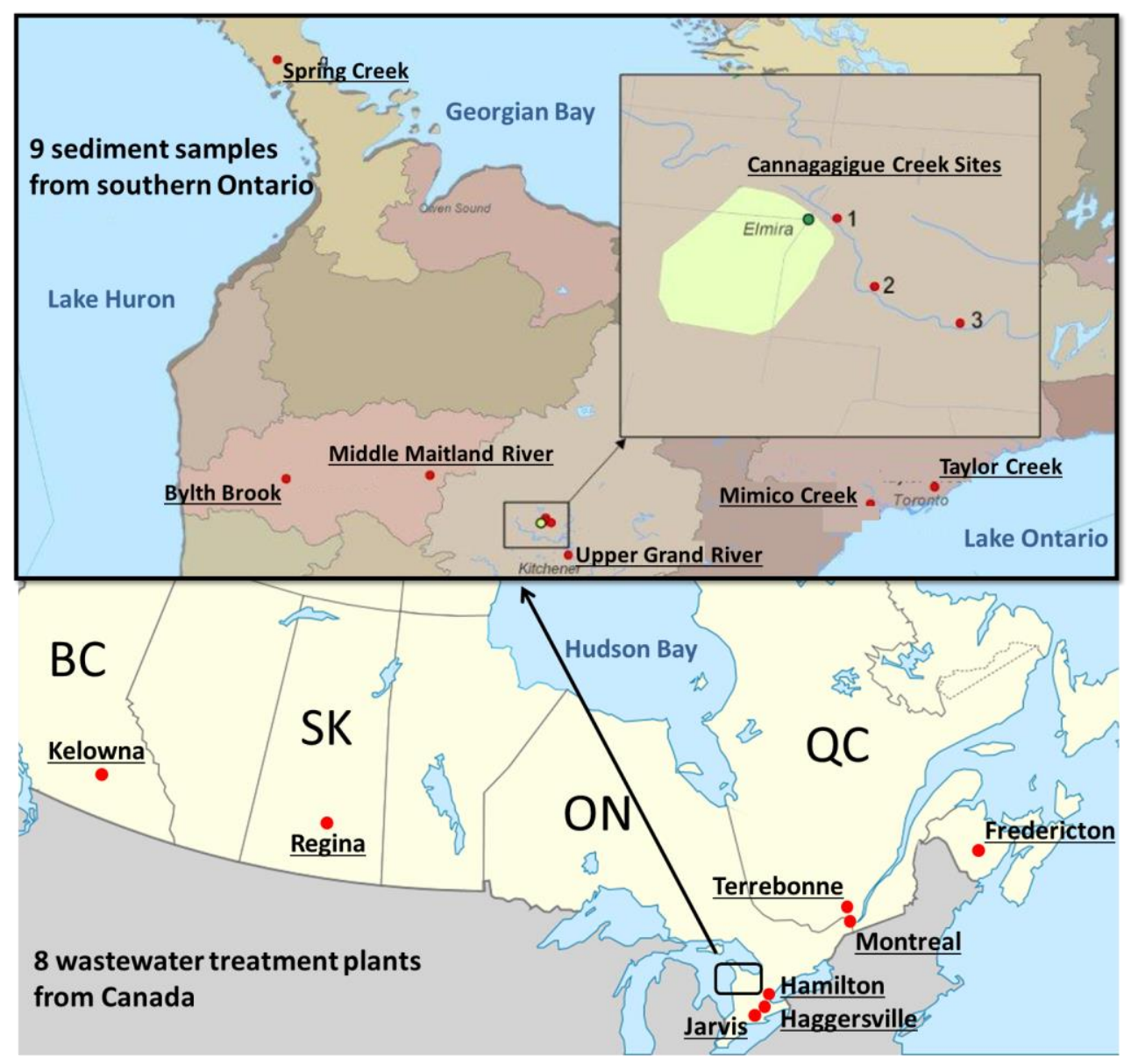

Fig S2. Nine collection sites of sediment samples \& 8 wastewater treatment plants' locations in the south of Ontario in Canada 


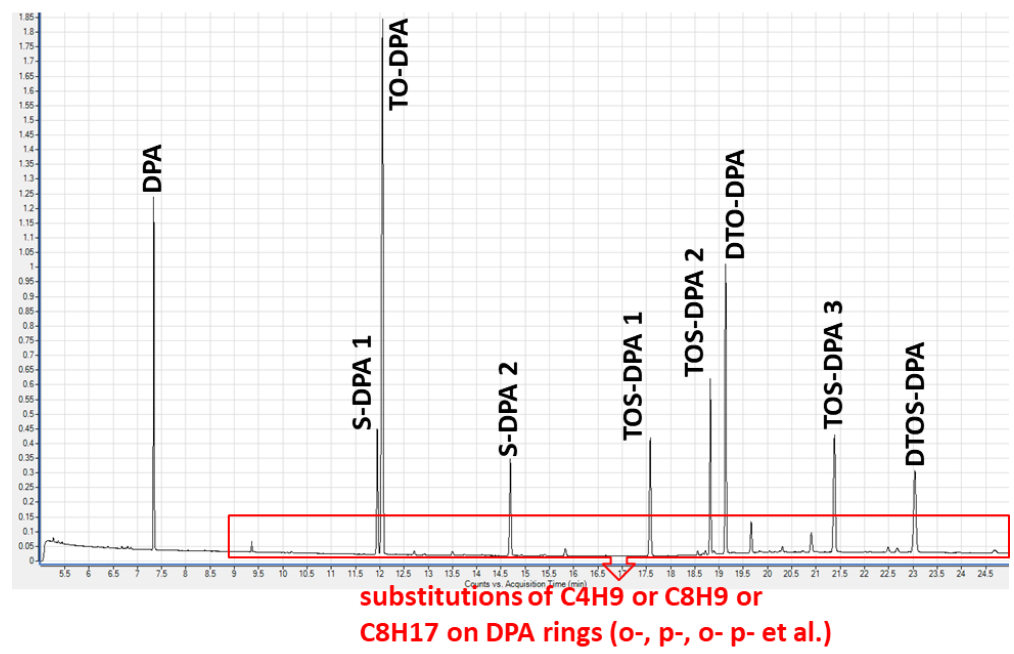

Fig S3. Chromatogram (GC-MS, full scan mode) of BNST 


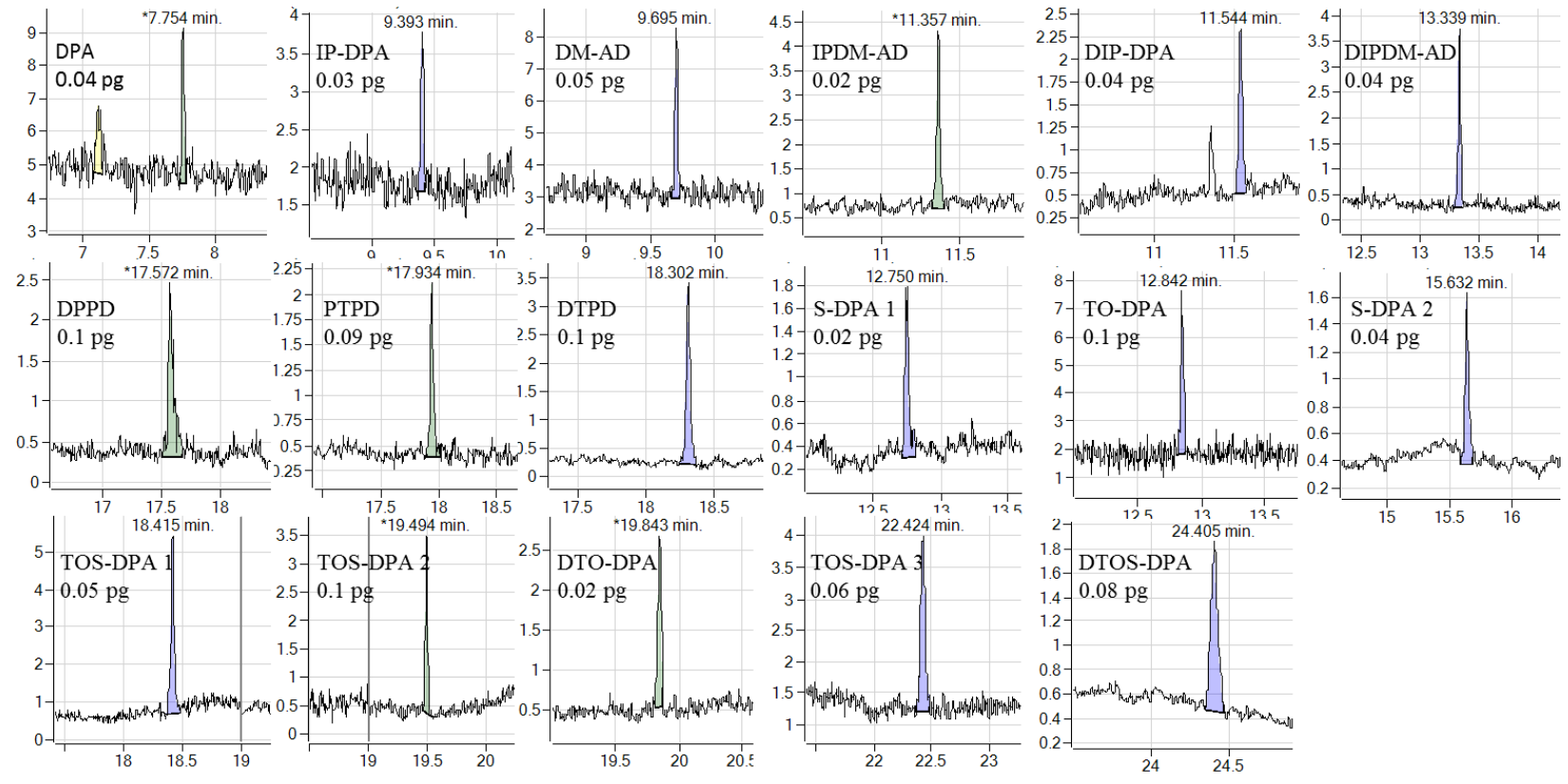

Fig S4. MS/MS chromatogram of LOD for all target compounds 